\title{
Expression of genes modulated by epigallocatechin-3- gallate in breast cancer cells
}

\author{
ANNA BOGACZ ${ }^{1,2 *}$, MARLENA WOLEK ${ }^{1}$, BOGNA JUSKOWIAK ${ }^{1}$, MONIKA KARASIEWICZ ${ }^{3}$, ADAM \\ KAMIŃSKI $^{4}$, IZABELA UZAR ${ }^{5}$, ANNA POLASZEWSKA ${ }^{1}$, ZOFIA KOSTRZEWA ${ }^{6}$, BOGUSŁAW \\ CZERNY ${ }^{1,5}$
}

\author{
${ }^{1}$ Department of Stem Cells and Regenerative Medicine \\ Institute of Natural Fibres and Medicinal Plants \\ Kolejowa 2 \\ 62-064 Plewiska, Poland \\ ${ }^{2}$ Department of Histocompatibility with Laboratory of Genetic Diagnostics \\ Regional Blood Center \\ Marcelińska 44 \\ 60-354 Poznań, Poland \\ ${ }^{3}$ Laboratory of International Health \\ Department of Preventive Medicine \\ Poznan University of Medical Sciences \\ Święcickiego 6 \\ 60-781 Poznań, Poland \\ ${ }^{4}$ Clinic of Pediatric Orthopedics \\ Pomeranian Medical University \\ Unii Lubelskiej 1 \\ 62-600 Szczecin, Poland \\ ${ }^{5}$ Department of Pharmacology and Pharmacoeconomics \\ Pomeranian Medical University \\ Żołnierska 48 \\ 71-230 Szczecin, Poland \\ ${ }^{6}$ Department of Anaesthesia, Intensive Care and Acute Poisoning \\ Pomeranian Medical University \\ Al. Powstańców Wielkopolskich 72 \\ 71-111 Szczecin, Poland \\ *corresponding author: e-mail: aniabogacz23@o2.pl
}




\section{Summary}

Introduction: Breast cancer is the most common malignant cancer among women. Both drug resistance and metastasis are major problems in the treatment of breast cancer. Therefore, adjuvant therapy may improve patients' survival and affect their quality of life. It is suggested that epigallocatechin gallate (EGCG) which is well known for its chemopreventive activity and acts on numerous molecular targets may inhibit the growth and metastasis of some cancers. Hence, discovering the metastatic molecular mechanisms for breast cancer may be useful for therapy.

Objective: The aim of the study was to determine the effect of EGGC on the mRNA expression level of genes such as ZEB1, ABCB1, MDM2, TWIST1 and PTEN in MCF-7 breast cancer cells.

Methods: MCF7/DOX were cultured in the presence of $0.2 \mu \mathrm{M}$ DOX and EGCG (20-50 $\mu \mathrm{M})$. The mRNA expression level was determined by real-time quantitative PCR using RealTime ready Custom Panel 96 kit.

Results: Our results showed an important increase (about 2-fold for $20 \mu \mathrm{M}$ EGCG $+0.2 \mu \mathrm{M}$ DOX and 2.5-fold for $50 \mu \mathrm{M}$ EGCG $+0.2 \mu \mathrm{M}$ DOX, $p<0.05)$ in $Z E B 1$ expression levels. In case of $A B C B 1$ gene lack of influence on the mRNA level was observed $(p>0.05)$. We also observed significant decrease of ZEB1 expression in MCF7 cells with $20 \mu \mathrm{M}$ and $50 \mu \mathrm{M}$ EGCG $(p<0.05)$. In addition, EGCG $(20 \mu \mathrm{M})$ caused an increase of MDM2 and PTEN mRNA levels in almost 100\% $(p<0.05)$ and $40 \%(p>0.05)$, respectively. Lack of the influence of EGCG was noted for the TWIST1 gene expression. In case of MCF7/DOX we showed an increase of mRNA level of PTEN gene about 50\% $(p<0.05)$.

Conclusions: These results suggest that EGCG may be potentially used in adjuvant therapy in the breast cancer treatment.

Key words: breast cancer, EGCG, molecular study, expression, adjuvant therapy

Słowa kluczowe: rak piersi, EGCG, badania molekularne, ekspresja, terapia adiuwantowa

\section{INTRODUCTION}

Breast cancer is one of the most common cancers among women. The incidence reaches about $25 \%$ new cases per year $[1,2]$. Although there is no effective drug for cancer, it is suggested that several ones can be prevented by healthy lifestyle, including diet modification. Many authors reported that some fruits and vegetables may negatively correlate with a risk of development of chronic diseases and several cancers [3-5]. Furthermore, the phytochemicals including phenolic compounds, carotenoids, contained in natural products have become a promising research topic in the prevention and treatment of cancer [6-8]. Recently, it was reported that the polyphenols are able to interrupt cellular signalling, especially NF- $\kappa \mathrm{B}$ and AP1 pathways, by scavenging reactive oxygen species (ROS) responsible for their activation $[9,10]$.

(-)-Epigallocatechin-3-gallate (EGCG) is one of the most studied catechins, well known for its favorable biological properties, like antioxidative potential [11]. Moreover, EGCG may induce apoptosis and inhibit growth of many human cancers, for example leukemia, colon cancer and breast cancer [12, 13]. Additionally, the in vivo studies assessing the effectiveness of EGCG against cancers are not always comparable with in vitro models due to differences in bioavailability of EGCG and ability to bind with target in cell [14, 15]. Many studies showed EGCG may inhibit MCF-7 cells proliferation by influencing the transcript level of hypoxia-inducible factor $1 \alpha$ and vascular endothelial growth factor [16]. In addition, EGCG may exhibit its anti-proliferation activity by the modulation of the PI3K-Akt pathway and Bcl-2 proteins, inhibition of some kinases (Cdk2, Cdk4) and activation of Cdk inhibitors p21 and p27 [17, 18]. However, although there are some interesting data concerning the activity of polyphenolic compounds against tumour cells, up to now little is known about their properties for breast cancer cells towards evaluation of genes such as: zinc finger E-box binding homeobox 1 (ZEB1), ATP-binding cassette, sub-family $\mathrm{B}(A B C B 1), \mathrm{MDM} 2 \mathrm{p} 53$ binding protein homolog (MDM2), twist homolog 1 (TWIST1), phosphatase and tensin homolog (PTEN) involved in apoptosis and proliferation. Therefore, the aim of the study was to determine the influence of EGCG on the expression of ZEB1, ABCB1, MDM2, TWIST1 and $P T E N$ in MCF-7 breast cancer cells. 


\section{EXPERIMENTAL}

\section{Study design}

Epigallocatechin gallate (EGCG) and doxorubicin (DOX) were provided by Sigma-Aldrich. The ERpositive breast cancer cell line, MCF-7 was obtained as a gift from Professor M. Zabel, Poznań University of Medical Sciences (Poland). The cell culture was carried out using Dulbecco's Modified Eagle Medium (DMEM-Gibco ${ }^{\oplus}$ ) (Sigma-Aldrich), with 10\% fetal bovine serum (Sigma-Aldrich) and $0.1 \%$ penicillin $(100 \mathrm{U} / \mathrm{ml}) /$ streptomycin $(100 \mu \mathrm{g} / \mathrm{ml})$ (SigmaAldrich) in incubator at $37^{\circ} \mathrm{C}$ with $5 \% \mathrm{CO}_{2}$ atmosphere.

MCF7/DOX were cultured in the presence of $0.2 \mu \mathrm{M}$ DOX. All cultures (MCF7, MCF7/DOX, MCF7/EGCG and MCF7/DOX/EGCG) were initiated at a density of $4 \times 100$ cells $/ \mathrm{ml}$ and grew for $160 \mathrm{~h}$ to reach the cell confluence. Thereafter, culture medium was removed and then cells were washed with PBS and incubated in culture medium without FBS in the presence of EGCG $(20-50 \mu \mathrm{M})$ for $24 \mathrm{~h}, 48 \mathrm{~h}$, $72 \mathrm{~h}, 96 \mathrm{~h}$, respectively. The effect of EGCG on cell growth and viability was assessed using a Bürker hemocytometer. Analysis of expression level of studied genes for different concentrations of EGCG was determined using real-time PCR.

\section{Expression analysis}

Total RNA extraction was performed using TriPure Isolation Reagent (Roche) according to the manufacturer's protocol. The quantitative assessment and purity of RNA were determined by a spectrophotometer (NanoDrop, Thermo Fisher Scientific). The cDNA synthesis was conducted from $2 \mu \mathrm{g}$ of total RNA using Transcriptor First-Strand Synthesis System (Roche) according to the manufacturer's protocol. The gene expression (ZEB1, ABCB1, MDM2, TWIST1, PTEN) was determined using RealTime ready Custom Panel 96 kit (Roche). Real-time PCR was conducted with use of LightCycler 96 Instrument (Roche, Germany) and a LightCycler ${ }^{\circledast} 480$ Probes Master kit (Roche, Germany) according to the manufacturer's protocol. As a housekeeping gene we used the ACTB gene for quantitative expression. The data were assessed using LightCycler ${ }^{\circledR} 96$ software.

\section{Statistical analysis}

The obtained findings were expressed as mean \pm SEM. Correlation analysis between the control and examined groups was performed using one-way ANOVA test. Value of $p<0.05$ was considered as statistically significant.

Ethical approval: The conducted research is not related to either human or animal use.

\section{RESULTS}

In this work, we studied the influence of EGCG on the mRNA level of selected genes in MCF-7 cells after $96 \mathrm{~h}$ with $20 \mu \mathrm{M}$ and $50 \mu \mathrm{M}$ EGCG (fig. 1). By performing real-time PCR reaction, we have found that MCF7/DOX and MCF7/DOX/EGCG are characterized by important increase (about 2-fold for $20 \mu \mathrm{M}$ EGCG $+0.2 \mu \mathrm{M}$ DOX and 2.5-fold for $50 \mu \mathrm{M}$ EGCG $+0.2 \mu \mathrm{M}$ DOX, $p<0.05)$ in $Z E B 1$ expression levels. In the case of $A B C B 1$ gene, we observed lack of influence on the mRNA level of this transporter as compared to control MCF-7 cells (fig. 1). What is interesting, we observed that the ZEB1 expression significantly decreased in MCF7 cells with $20 \mu \mathrm{M}$ and $50 \mu \mathrm{M}$ EGCG $(p<0.05)$. We also noted that EGCG $(20 \mu \mathrm{M})$ caused an increase of MDM2 and PTEN mRNA level about $100 \%(p<0.05)$ and $40 \%$ $(p>0.05)$, respectively. Similar effect was noted for administration of $50 \mu \mathrm{M}$ EGCG. In addition, we observed lack of the influence of EGCG on the TWIST1 gene expression in MCF7 cells in comparison to control group. Furthermore, in case of MCF7/DOX we showed an increase of mRNA level of PTEN gene in about 50\% $(p<0.05)$. We also assessed the influence of EGCG on cell growth by the use of a Bürker hemocytometer. We showed that EGCG in the analyzed concentrations did not affect the cell growth of MCF7 without DOX within 3 days after EGCG administration (80-100\% of control cell growth was observed in the presence of $20-50 \mu \mathrm{M}$ EGCG) (fig. 2). However, we observed the inhibition of cell growth after 4 days in case of $20-50 \mu \mathrm{M}$ EGCG administration.

\section{DISCUSSION}

Epidemiological studies show a relationship between green tea consumption and reduced risk of breast cancer $[19,20]$. The widespread interest of EGCG 


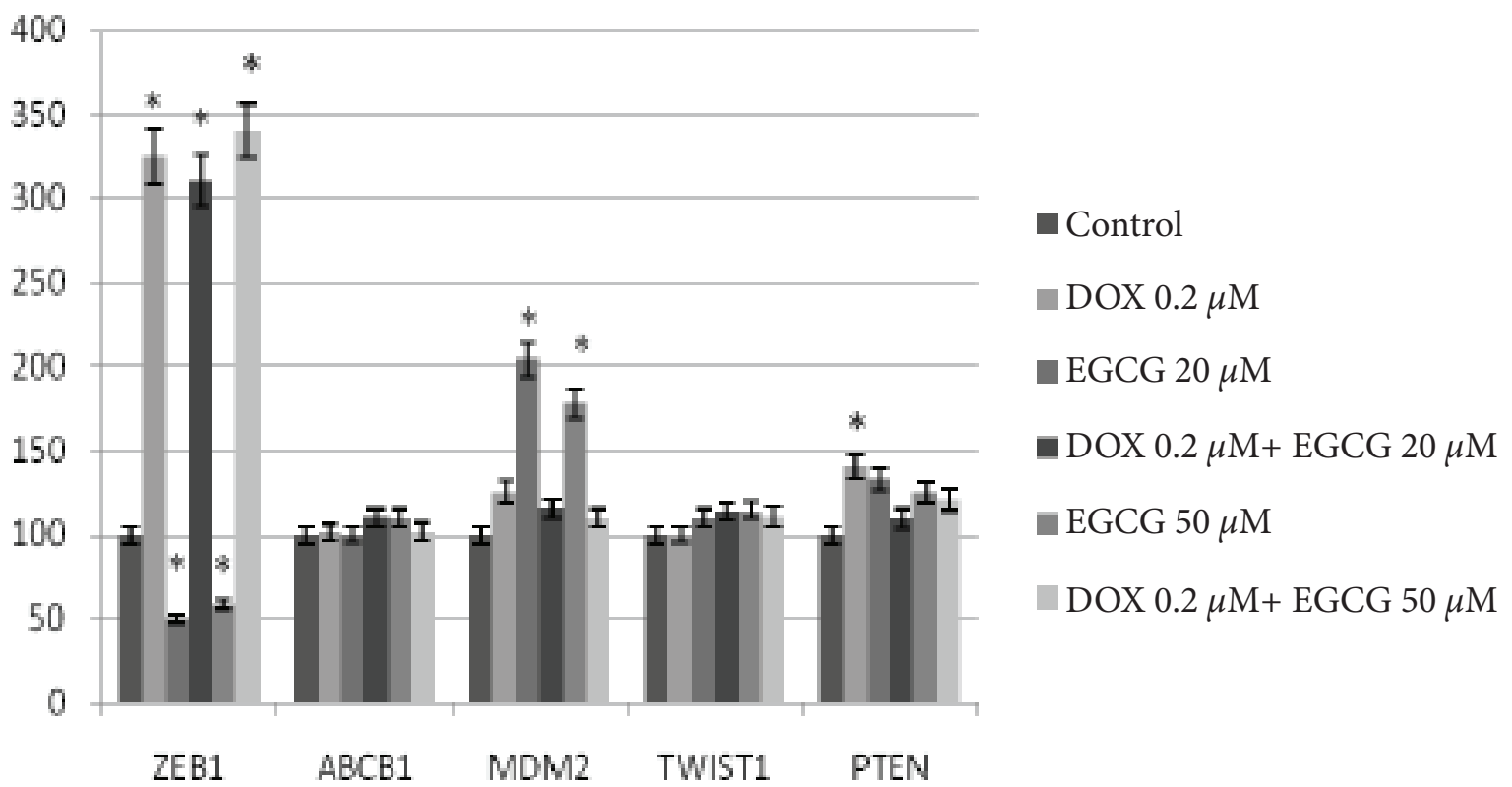

Figure 1.

Influence of epigallocatechin gallate (EGCG) and doxorubicin (DOX) on gene expression in MCF7 cells after 96 h. Control group was defined as $100 \%$. Data were presented as mean \pm SEM. ${ }^{*} p<0.05$ as compared with control group

\section{MCF-7}

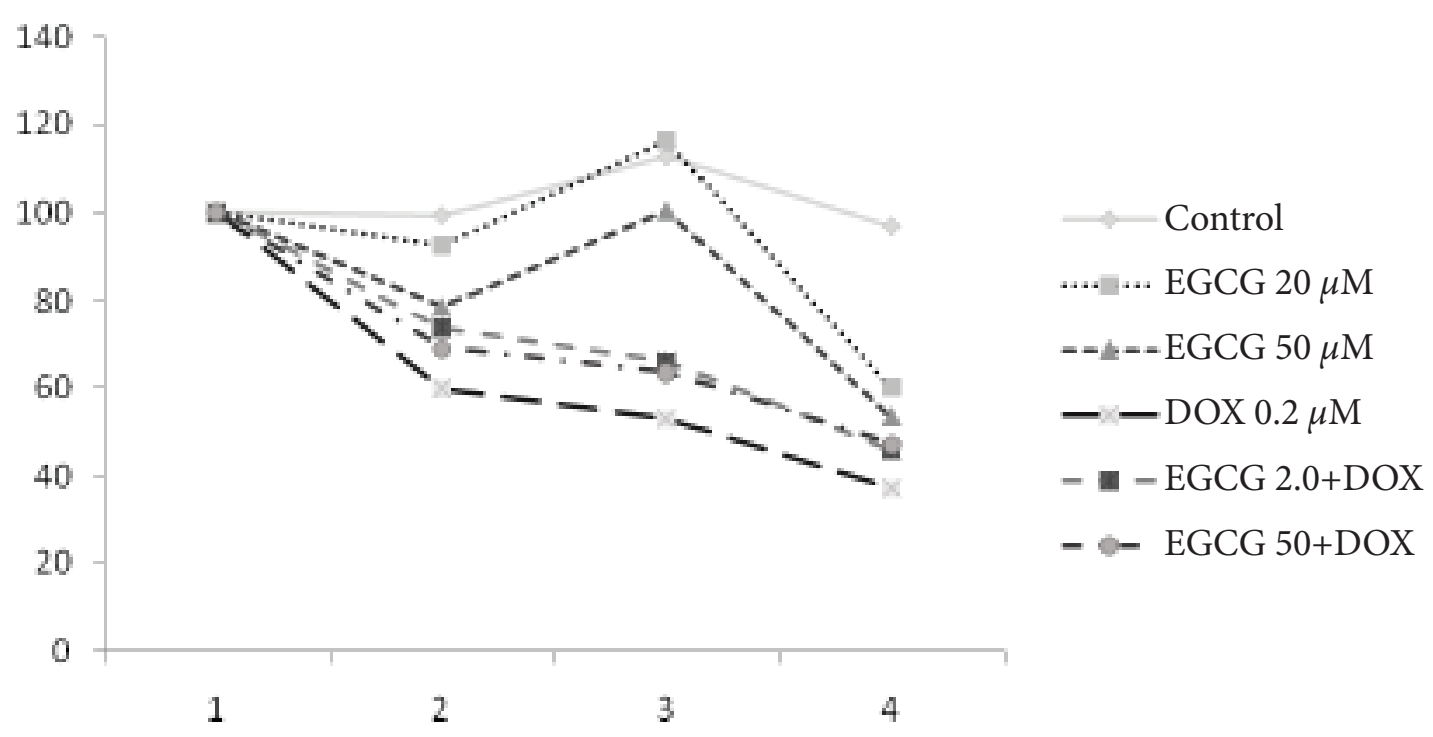

Figure 2.

Percentage of MCF7 cell survival after treatment with different concentrations of epigallocatechin gallate - EGCG (0, 20 and $50 \mu \mathrm{M})$, incubated for 4 days in presence or absence of doxorubicin-DOX $(0.2 \mu \mathrm{M})$. Control group without EGCG and DOX 
in prevention and treatment of breast cancer results from large number of data available based on in vitro and in vivo studies [21-23].

In our study, the effect of EGCG on the gene expression such as ZEB1, ABCB1, MDM2, TWIST1 and $P T E N$ in MCF-7 breast cancer cells was determined. We showed that MCF7/DOX and MCF7/DOX/ EGCG are characterized by important increase in ZEB1 expression levels in contrast to MCF7 cells with $20 \mu \mathrm{M}$ or $50 \mu \mathrm{M}$ EGCG alone. The ZEB1 gene encodes a protein called zinc finger E-box-binding homeobox 1 involved in metastasis, treatment resistance and poor survival of patients with different cancers [2426]. According to Brabletz et al., the increased ZEB1 expression in breast cancer was observed both for the type of triple negative (ER-, PR-, HER2-) and basal types of this cancer [25, 27]. Hence, it is suggested that $Z E B 1$ gene and its expression can be a predictor for assessment of patient survival.

Analyzing $A B C B 1$ gene encoding P-glycoprotein (P-gp) responsible for the efflux of many anticancer drugs, which may lead to chemotherapy failure and multidrug resistance, we observed lack of EGCG influence on $A B C B 1$ expression in MCF-7 cells. Another study showed that EGCG reduced the expression level of $A B C B 1$ in a dose-dependent manner (20, 40 and $80 \mu \mathrm{g} / \mathrm{ml}$ ) in the pancreatic PANC-1 cells, under hypoxic conditions [28]. However, these findings are ambiguous because hypoxia can also affect gene expression, including $A B C B 1$.

We also determine the effect of EGCG on the mRNA expression of MDM2 gene encoding a ring finger domain-containing protein. This protein may activation p53 ubiquitination as well as proteasomal degradation [29]. Moreover, the MDM2 expression may be also modulate in a p53-dependent manner. It was shown that the increase of p53 strengthens the $M D M 2$ expression which induces degradation of $\mathrm{p} 53$. In our study we observed that EGCG leads to an increase of MDM2 mRNA level. However, the mechanism of p53 regulation by EGCG requires further studies, because other researches showed an increase of p53 stability and a reduction of MDM2 accumulation in the cell nucleus after EGCG treatment [30].

Furthermore, we also analyzed the expression level of TWIST1 gene encoding the transcription factor TWIST, an oncoprotein which is an extensively studied regulator associated with cancer metastasis including breast cancer [31]. Another study showed that TWIST1 is a direct target gene of miR-320 in the ovarian cancer cell. It is claimed that overexpression of miR-320 regulating gene expression by influence of translation and stability of target mRNAs inhibits the cell proliferation of ovarian cancer [32]. Our findings showed a lack of the impact of EGCG on the TWIST1 gene expression in MCF7 cells. However, another study demonstrated that EGCG treatment reduces growth in human thyroid carcinoma cells depending on dose and causes a decrease of TWIST expression [33].

In addition, we determined the PTEN expression level as a potent suppressor gene involved in modulation of cellular functions, including proliferation, differentiation and migration. Activation of PTEN leads to inhibition of the PI3K/Akt/mTOR pathway responsible for tumour progression [34]. In our study, we showed that EGCG caused an increase of PTEN mRNA level in MCF7 cells in comparison to control group. It is suggested that EGCG may induce apoptosis in human breast cancer cells and influence their proliferation. Similar effect was obtained by Liu et al. indicating that EGCG leads to increase of PTEN expression and may inhibit the proliferation of pancreatic cancer cells. They also showed that EGCG may inhibit the PI3K/Akt/mTOR pathway by PTEN activation [34]. Another study also significantly showed an increase of the PTEN gene expression in variant T47D human breast cancer cells with high progesterone-receptor levels after EGCG treatment [35]. Hence, it is believed that EGCG may be potentially used in adjuvant therapy for the breast cancer treatment.

\section{CONCLUSIONS}

Our results provide new information on the effect of EGCG on the gene modulation associated with tumour cell proliferation, apoptosis and drug resistance. Additionally, based on our findings it may be suggested that a combination of EGCG with DOX treatment may enhance anticancer activity with no adverse side effects what may improve the quality of life in patients receiving chemotherapy. However, further studies are needed to provide evidence of practical application of EGCG in the cancers prevention and treatment.

\section{ACKNOWLEDGEMENTS}

The study was supported by statutory projects of the Institute of Natural Fibres and Medicinal Plants in Poznań, Poland.

Conflict of interest: Authors declare no conflict of interest. 


\section{REFERENCES}

1. Radecka B, Litwiniuk M. Breast cancer in young women. Ginekol Pol 2016; 87(9):659-663. doi: http://dx.doi.org /10.5603/GP.2016.0062

2. Siegel R, Jiemin MA, Zhaohui Z, Jemal A. Cancer statistics. Cancer J Clin 2014; 64(1):9-29. doi: http://dx.doi.org /10.3322/caac.21208

3. Liu RH. Health benefits of fruit and vegetables are from additive and synergistic combinations of phytochemicals. Am J Clin Nutr 2003; 78:517S-520S. doi: http://dx.doi.org /10.1093/ ajcn/78.3.517S

4. Liu RH. Whole grain phytochemicals and health. J Cereal Sci 2007; 46(3):207-219.

5. Liu RH. Health-promoting components of fruits and vegetables in the diet. Adv Nutr 2013; 4(3):384S-392S. doi: http://dx.doi.org /10.3945/ an.112.003517

6. Huang WY, Cai YZ, Zhang Y. Natural phenolic compounds from medicinal herbs and dietary plants: potential use for cancer prevention. Nutr Cancer 2009; 62(1):1-20. doi: http://dx.doi. org/10.1080/01635580903191585

7. Efferth T, Li PC, Konkimalla VS, Kaina B. From traditional Chinese medicine to rational cancer therapy. Trends Mol Med 2007; 13(8):353361. doi: http://dx.doi.org/10.1016/j.molmed.2007.07.001

8. Tapas A, Sakarkar D, Kakde R. Flavonoids as nutraceuticals: A review. Herba Pol 2010; 56(2):105-117.

9. Ramos S. Cancer chemoprevention and chemotherapy: dietary polyphenols and signalling pathways. Mol Nutr Food Res 2008; 52(5):507-526. doi: http://dx.doi.org/10.1002/mnfr.200700326

10. Sen T, Dutta A, Chatterjee A. Epigallocatechin3-gallate (EGCG) downregulates gelatinase- $\mathrm{B}$ (MMP-9) by involvement of FAK/ERK/NFkap$\mathrm{paB}$ and AP-1 in the human breast cancer cell line MDA-MB-231. Anticancer Drugs 2010; 21(6):632-644.

11. Stefaniak A, Sytykiewicz H, Czerniewicz P, Leszczyński B. Catechin-like antioxidative po- tential of selected tea products. Herba Pol 2012; 58(2):17-25.

12. Dube A, Nicolazzo JA, Larson I. Chitosan nanoparticles enhance the intestinal absorption of the green tea catechins (+)-catechin and (-)-epigallocatechin gallate. Eur J Pharma Sci 2010; 41(2):219-225. doi: http://dx.doi.org/10.1016/j. ejps.2010.06.010

13. Stuart EC, Scandlyn MJ, Rosengren RJ. Role of epigallocatechin gallate (EGCG) in the treatment of breast and prostate cancer. Life Sci 2006; 79(25):2329-2336. doi: http://dx.doi.org/10.1016/j.lfs.2006.07.036

14. Mereles D, Hunstein W. Epigallocatechin-3gallate (EGCG) for clinical trials: more pitfalls than promises? Int J Mol Sci 2011; 12 (9):55925603.

15. Klinski E, Semov A, Yan X, Alakhov V., Muyzhnek E., Kiselev V. Block copolymer-based composition of epigallocatechin-3-gallate with improved oral bioavailability as a way to increase its therapeutic activity. J Nanomedicine Biotherapeutic Disc 2013; 3:117. doi: http://dx.doi. org/10.4172/2155-983X.1000117

16. Luo H, Xu M, Zhong WT, Cui ZY, Liu FM, Zhou KY et al. EGCG decreases the expression of HIF$1 \alpha$ and VEGF and cell growth in MCF-7 breast cancer cells. J BUON. 2013; 19 (2): 435-439.

17. Qin J, Xie LP, Zheng XY, Wang YB, Bai Y, Shen $\mathrm{HF}$ et al. A component of green tea, (-)-epigallocatechin-3-gallate, promotes apoptosis in T24 human bladder cancer cells via modulation of the PI3K/Akt pathway and Bcl-2 family proteins. Biochem Biophys Res Commun 2007; 354(4):852-857. doi: http://dx.doi.org/10.1016/j. bbrc.2007.01.003

18. Liang YC, Lin-Shiau SY, Chen CF, Lin JK. Inhibition of cyclin-dependent kinases 2 and 4 activities as well as induction of cdk inhibitors p21 and p27 during growth arrest of human breast carcinoma cells by (-)-epigallocatechin3-gallate. J Cell Biochem. 1999; 75 (1): 1-12.

19. Sun L, Yuan JM, Koh WP, Yu MC. Green tea, black tea and breast cancer risk: a meta-analysis of epidemiological studies. Carcinogenesis 2006; 
27(7):1310-1315. doi: http://dx.doi.org/10.1093/ carcin/bgi276

20. Ogunleye AA, Xue F, Michels KB. Green tea consumption and breast cancer risk or recurrence: a meta-analysis. Breast Cancer Res Treat 2010; 119:477-484. doi: http://dx.doi.org/10.1007/ s10549-009-0415-0

21. Thangapazham RT, Singh AK, Sharma A, Warren J, Gaddipati JP, Maheshwari RK. Green tea polyphenols and its constituent epigallocatechin gallate inhibits proliferation of human breast cancer cells in vitro and in vivo. Cancer Lett 2007; 245(1-2):232-241. doi: http://dx.doi.org/10.1016/j.canlet.2006.01.027

22. Tran PL, Kim SA, Choi HS, Yoon JH, Ahn SG. Epigallocatechin-3-gallate suppresses the expression of HSP70 and HSP90 and exhibits anti-tumor activity in vitro and in vivo. BMC Cancer 2010; 10:276. doi: http://dx.doi. org/10.1186/1471-2407-10-276

23. Manjegowda MC, Deb G, Kumar N, Limaye AM. Expression profiling of genes modulated by estrogen, EGCG or both in MCF-7 breast cancer cells. Genomics Data 2015; 5:210-212. doi:http:// dx.doi.org/10.1016/j.gdata.2015.05.040

24. Bronsert P, Kohler I, Timme S, Kiefer S, Werner $\mathrm{M}$, Schilling $\mathrm{O}$ et al. Prognostic significance of Zinc finger E-box binding homeobox 1 (ZEB1) expression in cancer cells and cancer-associated fibroblasts in pancreatic head cancer. Surgery 2014; 156(1):97-108. doi: http://dx.doi.org/10.1016/j.surg.2014.02.018

25. Karihtala P, Auvinen P, Kauppila S, Haapasaari KM, Jukkola-Vuorinen A, Soini Y. Vimentin, zeb1 and Sip1 are up-regulated in triple-negative and basal-like breast cancers: association with an aggressive tumour phenotype. Breast Cancer Res Treat 2013; 138(1):81-90. doi: http:// dx.doi.org/10.1007/s10549-013-2442-0

26. Liu Y, Lu X, Huang L, Wang W, Jiang G, Dean KC et al. Different thresholds of ZEB1 are required for Ras-mediated tumour initiation and metastasis. Nat Commun 2014; 5:5660. doi: http://dx.doi.org/10.1038/ncomms6660

27. Brabletz S, Bajdak K, Meidhof S, Burk U, Nie- dermann G, Firat $\mathrm{E}$ et al. The ZEB1/miR-200 feedback loop controls Notch signalling in cancer cells. EMBO J 2011; 30 (4):770-782. doi: http:// dx.doi.org/10.1038/emboj.2010.349

28. Zhu Z, Wang Y, Liu Z, Wang F, Zhao Q. Inhibitory effects of epigallocatechin-3-gallate on cell proliferation and the expression of HIF- $1 \alpha$ and P-gp in human pancreatic carcinoma cell line PANC-1. Oncol Rep 2012; 27(5):1567-1572. doi: http://dx.doi.org/10.3892/or.2012.1697

29. Lee JT, Gu W. The multiple levels of regulation by p53 ubiquitination. Cell Death Differ. 2010; 17(1):86-92. doi: http://dx.doi.org/10.1038/ cdd.2009.77

30. Jin L, Li C, Xu Y, Wang L, Liu J, Wang D et al. Epigallocatechin gallate promotes p53 accumulation and activity via the inhibition of MDM2mediated p53 ubiquitination in human lung cancer cells. Oncol Rep. 2013; 29(5):1983-1990. doi: http://dx.doi.org/10.3892/or.2013.2343

31. Zhong J, Ogura K, Wang Z, Inuzuka H. Degradation of the transcription factor Twist, an oncoprotein that promotes cancer metastasis. Discov Med 2013; 15(80):7-15.

32. Li Ch, Duan P, Wang J, Lu X, Cheng J. miR-320 inhibited ovarian cancer oncogenicity via targeting TWIST1 expression. Am J Transl Res. 2017; 9(8): 3705-3713.

33. De Amicis F, Perri A, Vizza D, Russo A, Panno ML, Bonofiglio D et al. Epigallocatechin gallate inhibits growth and epithelial-to-mesenchymal transition in human thyroid carcinoma cell lines. J Cell Physiol. 2013; 228(10):2054-2062. doi: http://dx.doi.org/10.1002/jcp.24372

34. Liu S, Xu ZL, Sun L, Liu Y, Li CC, Li HM et al. (-)-Epigallocatechin-3-gallate induces apoptosis in human pancreatic cancer cells via PTEN. Mol Med Rep 2016; 14(1):599-605. doi: http://doi. org/10.3892/mmr.2016.5277

35. Moradzadeh M, Hosseini A, Erfanian S, Rezaei $\mathrm{H}$. Epigallocatechin-3-gallate promotes apoptosis in human breast cancer T47D cells through down-regulation of PI3K/AKT and Telomerase. Pharmacol Rep 2017; 69(5):924-928. doi: http:// dx.doi.org/10.1016/j.pharep.2017.04.008 